The Classic:

\title{
The Natural History Museum
}

Albert Eide Parr

1939: "- if we do recognize that one of the main research missions of a natural history museum lies in the ecological types of investigation, we must obviously also admit the perfect appropriateness of handling live, as well as dead material, in the museum to the extent that the observations on the living individuals may tend to confirm or to explain the conclusions arrived at by the study of the preserved samples of natural populations."

1950: "The side of nature which concerns society most of all is not undisturbed nature, but nature as the environment of man, and that is the field in which the educational efforts of the natural history museums could make their greatest contribution to human thought, welfare, and progress today."

1980: "- it seems clear that museums, at least in the larger cities, may be more important as independently explorable additions to the environment itself, than in the simple role of didactic interpreters of experiences gained from other sources."

\section{THE NATURAL HISTORY MUSEUM TODAY \\ (From 'On the Function of the Natural History Museum', 1939)}

The natural history museum of today can no longer claim justification by the mere existence of its collections. After a period of indiscriminate expansion which has been virtually unbroken since its early beginnings, the museum has entered into an era of consolidation and evaluation of its functions. It is therefore of urgent necessity to attempt to find a clear-cut expression for the services which a museum of natural history is capable of rendering and for the need of society to have these services performed.

It has been obvious for some time that the modern museum has to seek its sup-

Albert Eide Parr (1900-1991) was born in Bergen, Norway. Here he also studied Marine Biology as an assistant to Professor August Brinkmann at Bergen's Museum. In his twenties he left Norway and emigrated to the United States. From what he later told the reason was that he wanted to marry, and could see no future in his homeland, where the whole country was in a state of economic depression.

In 1926 he started as an assistant at the New York Aquarium. He continued his research in Marine Biology and in 1938 he was appointed director of the Peabody Museum at Yale University. There he also served as 
AlBERT EIDE PARR

148

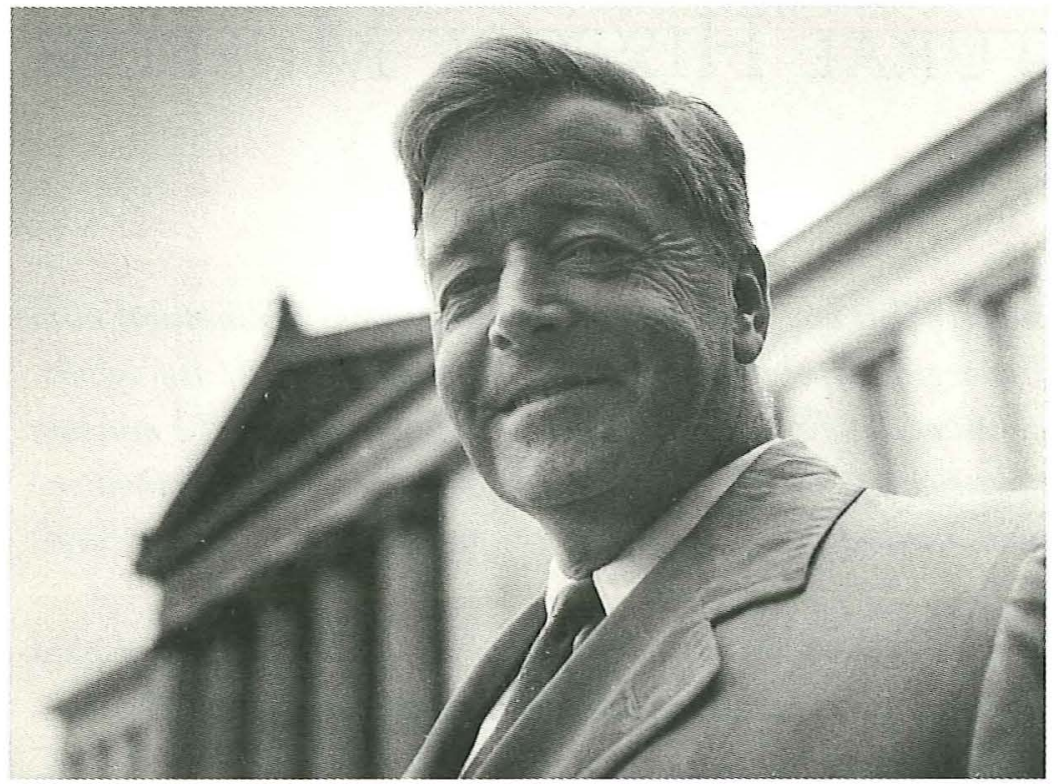

Albert Eide Parr (19001991), photo in Oslo 1959 by Bjorn Fjortoft.

Professor of Oceanography. Four years later he became director of the American Museum of Natural History, a post he held until 1959. From then until his retirement in 1968 he worked as a senior scientist at the museum. He was President of the American Association of Museums and became well-known for bis books and articles on museological subjects. At the age of 80 Parr was made the first recipient of 'The Award for Distinguished Services to Museums' by the Council of the American Association of Museums

A. E. Parr got his first important experience of museums in Bergen during his childhood. Actually Bergen's Museum, established in 1825 as the first 'real' museum in Norway, in the beginning of this century still had to be considered the most advanced Norwegian museum. Gradually it however split up into several small museums and a university. Later Parr reflects upon the difference between visiting museums with a "class in session" and his quite voluntary museum visits in Bergen:

«... among the fondest memories of my childhood are my independent and unguided visits to museums, entirely on my own, even before I reached the age of kindergarten. During the following years I passed a number of museums daily on my walks between home and school, and visited them alone, regularly enough to become well known to their guards. I wish that every young person could have the same opportunities (Parr 1980)”.

In his museum work and in numerous articles Parr developed far-reaching ideas on the role of museums, - and very early he emphasized the importance of ecology in the natural history museums. Perhaps his childhood experiences in the multidisciplinary Bergen's Museum were useful; though he worked in the field of natural history museums, it was the cultural role of museum work that was his main interest.

Three extracts, representing three different periods, have been selected to give an idea of A. E. Parr's thinking. In the extract from 1939 Parr discusses the functions of the natural history museum. In an article from 1950 the relationship between man and nature is the subject for his reflection. The third extract is from the speech given in 1980 when he received the AAM award.

In 1939 he discusses the ecological perspective in the natural history museum. In 1980 he discusses the similarities between art museums and natural history museums: "... art and nature are the main sources of beauty in our lives». Is that still a matter of concern to the museums of nature? (JAG) 
port from an ever-widening segment of the population and can no longer be fully maintained by the generosity of the few.

These are facts of great significance. They mean that the museum can no longer devote its effort entirely to the satisfaction of the abstract scientific curiosity for which a full appreciation can only be found within a comparatively small group of enthusiasts in all walks of life. Instead, an increasing emphasis must be placed upon the treatment of the more concrete problems in man's relation to nature which are of common concern to all mankind.

The possible functions of the natural history museum can be divided into four categories. At one extreme, we have its functions for or in research. At the other extreme its pure entertainment value. In between, we have the museum's services in support of formal education in other educational institutions, and its maintenance of an independent educational program of its own.

\section{RESEARCH}

In relation to research the museum of natural history has a dual set of functions to perform. It serves as an archive for the preservation of the evidence of conclusions already arrived at. It is also expected to form the center of active research towards new conclusions. These dual purposes are not in harmony but in competition, each being a burden upon the other. In this internal conflict there is grave danger to the effective functioning of the museum. [---]

In trying to determine the entire scope of research functions which will provide the fullest and best utilization of all its facilities, it may be well to consider the totality of the museum as though it were a single instrument. On this basis we may say that, just as the proper functions of a microscope are determined by its ability to magnify very small objects, so also may the proper research functions of the entire museum be determined by its special ability to handle natural history objects in large quantities. Since this ability, peculiar to the museum as a whole, fulfills one of the primary needs peculiar to the statistical fields of research, such as ecology and population studies in general, it is logical to see in the pursuit of this type of investigations the primary research function of the natural history museum. In a vast field of ecological problems, preserved samples offer the same advantages over the attempts to observe living nature as those found in a series of stills culled from a motion picture film covering action too complex to be analyzed in movement. Preserved samples also offer other great advantages in the concentration of evidence and reduction of dimensions in space, which are essential for the practical undertaking of ecological research. Of course, if we do recognize that one of the main research missions of a natural history museum lies in the ecological types of investigation, we must obviously also admit the perfect appropriateness of handling live, as well as dead material, in the museum to the extent that the observations on the living individuals may tend to confirm or to explain the conclusions arrived at by the study of the preserved samples of natural populations. 


\section{PLEASURE AND RECREATION}

In regard to the museum's place among the so-called "entertainment industries," I do not see anything objectionable about frankly acknowledging that we do not only teach but also simply entertain. It is hardly necessary to point out that in combining these two functions we are in the most excellent and highly respected company. Our type of entertainment is sound and, when well done, of considerable intrinsic value to the human imagination, perhaps particularly to the developing minds of the young. We should be perfectly entitled to take pride in this fact and to expect society to take some interest in our activities for their genuine entertainment value alone, even if no other services were offered.

\section{THE MUSEUM'S MESSAGE (From 'On Museums of Nature and Man', 1950)}

\section{As the Twentieth Century progressed:}

Habitable virgin territory was scarcely to be found any more within the reach of western civilization. Migration and colonization had tapered off. Those seeking to better their circumstances, or find a more acceptable way of life elsewhere, had to think in terms of joining other communities in lands already brought under cultivation. And nature had struck back at her exploiters in a series of dramatic blows delivered in almost all parts of the world. Even for those whose interests were largely limited to home territory, vanishing soils, diminishing resources, fluctuating fisheries, and other limitations and handicaps imposed by nature became a matter of much deeper concern than the fate of vanishing species, much as also these might be missed.

Human influence extended everywhere, and man's greatest and most direct concerns about nature were in regard to the effects of that influence both upon nature and upon man himself. But the natural history museums generally took very little account of these growing problems of civilization, and continued their overwhelming, and often exclusive, emphasis upon nature undisturbed by man, upon the rare and peculiar, upon that most vaunted possession of all - the extinct species, which can no longer affect human life one way or another - and upon the many interesting subjects deriving their significance from the theory of evolution, such as comparative anatomy, classification, biogeography, and others.

That these subjects are technically essential for the progress of science, and retain a high value for general education, we, as professionals, all know. And I wish to make it perfectly clear that I am firmly convinced of the absolute need for continuing them in the programme of our museums. But I am equally convinced that they are far from constituting an adequate programme in the light of modern conditions, and far from fulfilling the duties which our opportunities give us to be of service to a troubled world.

It is only through our service to the world at large that we shall be able to earn the support we need for our continued existence and the further development of our functions. The world of science alone cannot provide it. And from the layman's point of view it is, perhaps, not unreasonable to feel that he has already paid a 
fairly generous bill for having had his unfortunate ancestry pointed out to him, and to ask how the rare, peculiar, and undisturbed relates to his own hopes and aspirations in a very disturbed world. It is true, of course, that he still remains our friend, that the number of our friends is increasing, at least in many parts of the world, that they derive inspiration from what we show them, and consider our offerings very "nice» and "interesting." But I am afraid that it is equally true that they have come to doubt whether we are also essential. The existence of such doubts has certainly found many expressions in concrete actions, and even more abundantly in lack of action by the public on behalf of their natural history museums.

To re-establish our position we must find, and adopt, a new mission, and develop a more complete and better balanced programme with a more direct bearing upon the urgent problems of contemporary existence.

Probably most of us have seen the need and recognized our duty, but have hesitated before it. The side of nature which concerns society most of all is not undisturbed nature, but nature as the environment of man, and that is the field in which the educational efforts of the natural history museums could make their greatest contribution to human thought, welfare, and progress today.

Many museums have already made scattered progress towards the task before us, some starting quite far back. But what has been offered is usually quite parenthetic, and often presented in a rather apologetic manner. It seems to me essential for the effectiveness of our services to society, and for our own benefit in return, that we all acknowledge as one of the foremost reasons for our existence, the task of explaining to man the problem of his own relationship to his very disturbed and disturbing environment, and that we then proceed with the task as rapidly as possible.

Within a programme oriented towards that end, all the other subjects we are already pursuing would find their natural places, and an increased justification to boot. A knowledge of undisturbed nature is essential for an understanding of how it has been changed and may change again. An understanding of evolutionary processes, classification, genetics, and so on, becomes indispensable.

It is not necessary to enlarge upon the details of the subject of man and nature. Each of us knows the problems of his own nation and his own country. Striking examples of disturbing aspects in the relationship between man and nature immediately spring to mind - drought and dustbowls, increasing deer populations, diminishing fisheries and forests, floods and diminishing water resources, and many other symptoms of profound alterations in the ecology of the environment, directly or indirectly caused by man, who is, in turn, affected by the consequences. These things we should try to elucidate in order to help achieve a better adjustment between the aspirations of man and the possibilities of his environment. But these are only the special cases, the spectacular events interspersed in a continuous quiet struggle. Our main task should be to explain the normal, everyday functioning of familiar nature before the eyes, and under the hand of man, for the increased pleasure and enjoyment of those who turn 
152 to nature for physical and mental recreation, and the increased benefits of those who derive their support directly from the environment.

In undertaking this task we would also fill a social need of growing importance. In a democracy we all have an equal share in determining our nation's policies and practices in regard to the country which forms the basis of national existence. But increased urbanization tends towards a reduced understanding of the actual problems of the land on the part of a large segment of the population, steadily gaining in size and importance. Ignorance, or indifference bred by remoteness from the daily realities involved, may thus broaden the latitude for ill-advised action on the national level, and deepen the misunderstandings between town and country which are always, at least potentially, present. The efforts we may direct towards the presentation of nature as the environment of man would therefore not only be of welcome significance for the individual, but might also make a real contribution to improved national harmony.

Extending this thought into the field of international relations we finally come to the most urgent and compelling reason for making our museums tell a coherent and integrated story of "Man and Nature» rather than continuing to deal only with the separate subjects of Ethnography and Natural History.

\section{ON MUSEUMS OF ART AND OF NATURE \\ (From 'On Museums of Art gnd of Nature', 1980)}

As our evolving culture and technology change our style of living, they also change the demands our society will or should, make upon its cultural institutions, including our museums. And every time new goals are added, or substituted, they almost invariably push the pendulum of our institutional value systems too far in the new directions. Of course, the response varies from one institution to another, and it has very recently dawned upon me that the evolution of museums of art and of natural history museums, which in the beginning were virtually the same except in regard to the treasures in their custody, has led to fundamental differences of philosophies and functions, to the general advantage of the art museums. Still, all museums tend to overreact to new values and purposes, and today I find myself inclined to rebel against what has become of many of the things that I joined in the fight for years ago.

Considering the fact that art and nature are the main sources of beauty in our lives, it is not too surprising that an emphasis upon esthetic appeal over cognitive significance should not merely characterize the collections and exhibits of art museums, but also those of natural history museums, from their early beginnings well into the present century. We have all been exposed to large collections and extensive displays of butterflies, beetles and seashells, with very few flies, fleas and worms found in the same halls.

As the accrual of collections continued, 
the care, use and presentation of their contents gained in importance, while the tasks of acquisition became more sharply defined, less challenging, and less demanding upon the time of those responsible for the museum's performance. "Curator" was no longer simply another word for an institutionally employed collector. With collections largely inherited from the amassments of others, the excitement of discovery and accumulation began to yield ground to fascination with the meaning and messages contained in the objects. Museums stopped serving primarily as means of expressing the collectors' interests and values, to become channels of communication between the artists and the public, and between nature and humanity. In natural history museums, this conscious or subconscious concept of their function found its ultimate expression in habitat groups on the scale of entire landscapes.

But soon, museums of art and of nature reached a parting of their ways. While the art museums continued to concentrate upon their mission as media of communication for the creators of the arts, nature was evidently not eloquent enough for the role of main speaker in the natural history museums. In the name of education, these museums sought new and expanded parts for themselves as interpreters and spokesmen for nature, leaving less and less opportunity for simple and direct exposure to the affective as well as the cognitive messages of the natural environment, as contained in its objects and images.

The real and potential contributions of museums to our educational processes in their broadest sense are, of course, immense and invaluable. I have often enough argued in their favor in the past. But as the 153 cause of education has gained approval and influence, it has also changed its sense of purpose and of proportions, until its impact upon the styles of presentation in the natural history museums often begins to seem more detrimental than beneficial for their general public appeal.

We seem to be forgetting that the prime function of museums is not the mass production of standardized curricular knowledge, but that it always was, and always should be, to offer enjoyable and rewarding stimulation for individual minds in their hours of freedom from their daily chores. If anyone should consider it derogatory to speak of museums as places of entertainment for the hours of leisure, let us remind ourselves that the so-called "entertainment industry» also includes theaters and concert halls presenting the works of Ibsen and Shakespeare, Beethoven and Tchaikovsky. We could hardly find ourselves in better company.

As their educational ambitions have grown, the natural history museums often seem to have lost their concern for much of the potentially unlimited human spectrum of their attendance, and for the great possibilities of their own unique means of addressing their audiences. Labels and diagrams grow and multiply in the exhibits, trying to lead your attention away from the beauty or fascination you might find in the objects themselves. The words and drawings will tell you what you are supposed to learn about the specimens before you, rather than from them. The specimens often seem to be there only as reminders that the museum is trying to teach about real things in a reliable threedimensional textbook. A similarly dense 
ALBERT EIDE PARR

154 foliage of labels is rarely, if ever, found in art museums.

But few people are inclined to read textbooks for fun and pleasure. To most adults no longer impaled upon an «educational» schedule, the greatest joy of a museum visit is to explore your own visions of what you see, without simply having to think what you are told to think about the sights before you. And this is probably also true of visitors of any age who are entirely free to respond to their own preferences rather than the expectations of others. Be that as it may, however, if the written word, with appropriate diagrams, does not suffice to catch and control the attention of the visitors, one can always add a verbal electronic din in their ears to prevent the danger of personal thoughts and feelings about what is there for the eyes to see. [---]

In earlier days, one of the most important contributions of a natural history museum may have been to serve as a source of enlightment about the visitors' daily or, at least, very frequent experiences of the natural environment. In small towns this is true even today. But as the cities grow larger, the opportunities for exploration and exciting discoveries in nature, as well as in the streets, become fewer and poorer in content, particularly for the young, who do not have the independent mobility of their elders. A bus ride to school, confined among the other pupils, does not offer the varied and exhilarating human experiences of walking to school in streets shared by all ages, or commuting with them in the vehicles of general public transportation. And even if you do make your way on foot, the diversity of other people around you is only a minute frac- tion of what it was before the age of supermarkets and private cars. The physical cityscape through which we must walk, when we have to, has also suffered an enormous loss of varied stimuli for our senses to absorb and our minds to feed upon.

As a consequence of these developments, it seems clear that museums, at least in the larger cities, may be more important as independently explorable additions to the environment itself, than in the simple role of didactic interpreters of experiences gained from other sources. In these circumstances it seems very offensive that so many of our metropolitan museums, which not so long ago were freely open to all visitors, now charge admission even for children, unless they are included in a visiting class directed by a teacher or a docent. In partial compensation for the decline of the street as a stimulating habitat for the young, our communities are continuously creating new playgrounds for the physical needs of young bodies, at the same time as they are increasingly restricting access to the best fields of exploration available for young minds within the environment in which they are growing up.

\section{REFERENCES}

The complete texts are:

Parr, Albert Eide, "On the Functions of the Natural History Museum,» Transactions N.Y. Acad. Sci., Dec. 1939, also printed in Parr, Albert Eide, Mostly About Museums, New York 1959

Parr, Albert Eide, "Museums of Nature and Man,"

The Mus. Jour., Vol. 50, Nov. 1950, also printed in Parr 1959

Parr, Albert Eide, "On Museums of Art and of

Nature», Museum News October 1980 